\title{
Neurofibromatosis type 1 in childhood: correlation of MRI findings with intelligence
}

\author{
E Legius, M J Descheemaeker, J Steyaert, A Spaepen, R Vlietinck, P Casaer, P Demaerel, \\ J P Fryns
}

\begin{abstract}
In a group of 28 children with neurofibromatosis type 1 aged between 4 and 16 years, neuroradiological findings were correlated with intelligence as measured by the Wechsler scales. The presence or specific location in the brain of $T 2$ weighted prolonged signals on MRI was not associated with cognitive problems. No other physical characteristics associated with neurofibromatosis type 1 were found to correlate significantly with IQ. At the present these $\mathrm{T} 2$ weighted hyperintense spots should not be used to predict neurofibromatosis type 1 associated cognitive problems.
\end{abstract}

$(F$ Neurol Neurosurg Psychiatry 1995;59:635-640)

Keywords: neurofibromatosis type 1; magnetic resonance imaging; intelligence; high intensity lesions; brain

Neurofibromatosis type 1 or Von Recklinghausen's disease is a common autosomal dominant disorder with a frequency of 1 in 3000 , a complete penetrance with variable expression, and a high spontaneous mutation rate. ${ }^{1}$ The neurofibromatosis type 1 gene is cloned and resides on chromosome 17 $(17 \mathrm{q} 11 \cdot 2) .^{2}$ In children café au lait spots and inguinal or axillary freckling are often seen. Enhanced T2 weighted foci on brain MRI are reported in $50 \%$ to $74 \%$ of children with neurofibromatosis type 1 and are most often seen in the basal ganglia, cerebellum, and brain stem..$^{3-6}$ The nature of these enhanced T2 weighted foci in the brain is not known.

In children with neurofibromatosis type 1 the mean full scale intelligence quotient (FSIQ) is shifted to the left and is situated between 88 and $94 .{ }^{1-11}$ In addition to a somewhat lower FSIQ several studies described visuospatial integration deficits as well as an increased incidence of school performance problems. ${ }^{7-14}$ The cause of these neurofibromatosis type 1 related cognitive problems is unknown and several studies failed to show a relation between the often seen $\mathrm{T} 2$ weighted hyperintense foci in the brain and cognitive problems in neurofibromatosis type $1 .^{3-5}$ Two recent studies, however, suggest a negative effect of enhanced T2 weighted foci in the brain on FSIQ and other aspects of cognitive functioning in patients with neurofibromatosis type $1 .{ }^{15} 16$

In this study we correlated findings of brain MRI with intelligence in a group of 28 children with neurofibromatosis type 1 .

\section{Materials and methods}

A group of 28 children (15 boys; 13 girls) between 4 and 16 years old was tested with the Wechsler scales for intelligence (WPPSI, WISC-R) by one educational psychologist (MJD). The intelligence profile of these children has already been reported. ${ }^{11}$ All children met NIH criteria for neurofibromatosis type $1 .{ }^{17}$ The group of 28 children were followed up at the Leuven neurofibromatosis clinic for children and all children were physically examined by two clinicians (AS, EL). Brain MRI was performed at 1.5 Tesla (Siemens, Erlangen). Unenhanced axial T2 weighted and $\mathrm{T} 1$ weighted spin echo images were routinely obtained in all patients. Gadopentate dimeglumine was given intravenously and additional axial, coronal, and sagittal T1 weighted images were obtained in cases with suspected or pathological areas.

Specific regions of interest on MRI were analysed for the presence of enhanced T2 weighted foci. Regions of interest were: the different cerebral lobes, basal ganglia, thalamus, brain stem, cerebellar hemispheres, vermis cerebelli, and internal capsule. Homologous regions in the right and left hemispheres of the cerebrum and cerebellum were considered as one region of interest. Only spots that were not seen in other phases of MRI were considered as enhanced T2 weighted foci.

The means of continuous variables of two different groups of children were compared by two tailed $t$ test. Correlation between two continuous variables was calculated according to Pearson. Analyses of covariance (ANCOVA) were performed with FSIQ as dependent variable, and the number of $\mathrm{T} 2$ weighted foci or each of the regions of interest separately as independent variable. Age and the presence of neurological abnormalities were taken as covariates in these analyses

\section{Results}

The mean FSIQ of the group of 28 children with neurofibromatosis type 1 was 89 (range 
Table 1 Full scale IQ (FSIQ) according to different grouping variables

\begin{tabular}{lrrl}
\hline & No & FSIQ (SEM) & P value ( t test) \\
\hline Boys & 15 & $92 \cdot 8(3.6)$ & NS \\
Girls & 13 & $85 \cdot 0(7 \cdot 1)$ & \\
UBO+ & 18 & $90 \cdot 2(4 \cdot 8)$ & NS \\
UBO- & 10 & $87.5(6.5)$ & \\
Neuro+ & 8 & $74.5(6 \cdot 4)$ & 0.012 \\
Neuro- & 20 & $95 \cdot 1(4 \cdot 1)$ & \\
Neuro-UBO+ & 10 & $102 \cdot 7(5 \cdot 6)$ & 0.076 \\
Neuro-UBO+ & 10 & $87.5(5 \cdot 6)$ & \\
\hline
\end{tabular}

$\mathrm{UBO}+$ or UBO - = those children with or without hyperintense T2 weighted foci on MRI of the brain (UBO= unidentified bright object), Neuro + or Neuro $-=$ those children with or without other neurological abnormalities, the bottom row of the table refers to the FSIQ of children without other weighted foci on brain MRI (Neuro - UBO + or -).

54-148), with a mean verbal IQ of $95 \cdot 7$ and a mean performance IQ of $84 \cdot 1$ (paired $t$ test, $\left.P=2 \times 10^{-5}\right)$. The mean age of the children was 9 years and 4 months.

Eight children (four boys and four girls) were found with neurological diseases (two had epilepsy, two hydrocephalus, one a brain stem glioma with hydrocephalus and epilepsy, one an interhemispheric frontal tumour, one a congenital hemiparesis, and one had received irradiation because of bilateral and chiasmatic optic pathway glioma). As expected these eight children scored significantly lower on IQ tests than the other 20 children without neurological disease (table $1)$.

Brain MRI was scored for the presence and specific location of enhanced T2 weighted foci. In 18 of 28 children hyperintense T2 weighted spots were seen. These 18 children had a mean FSIQ comparable with the 10 children without spots (table 1). The eight children with neurological diseases all showed the typical T2 weighted spots, and only 10 of the 20 children without any evidence of neurological disease showed them $(P=0.025$; Fisher's exact test). In the group of children without neurological disease the 10 children with increased T2 weighted signals showed a higher mean FSIQ than the 10 children without (table 1).

In this group of 28 children ANCOVA with age and the presence of neurological abnormalities as covariates, showed no significant relation between the number of $\mathrm{T} 2$ weighted foci in the brain and FSIQ (table 2). Similarly, ANCOVA with the same covariates showed no relation between a specific location of T2 weighted hyperintensities and
FSIQ (table 2). ANCOVA was not performed for temporal lobe, occipital lobe, parietal lobe, and vermis cerebelli, as the number of patients with enhanced T2 weighted foci in these regions of interest was one or zero.

\section{Discussion}

In the present study we could not find a relation between the presence or absence of T2 weighted hyperintens foci in the brain and scores on the Wechsler scales of intelligence. We identified a group of eight patients with neurofibromatosis type 1 who had other neurological disease and a significantly lower FSIQ. These eight children all had T2 weighted hyperintensities in their brains. The presence of neurological abnormalities in the eight children is likely related to neurofibromatosis type 1 , although it is possible that some are coincidental. The 20 children without other neurological disease had a near normal FSIQ $(95 \cdot 1)$, and T2 weighted enhanced foci in the brain were present in 50\% (10/20). Enhanced T2 weighted foci in this group without neurological disease were associated with a higher FSIQ. In addition there was no significant correlation between the number or location of T2 weighted foci in the brain and FSIQ.

Three other studies did not find a relation between enhanced T2 weighted foci and cognitive problems. Dunn and Roos ${ }^{3}$ could not find any association of hyperintense T2 foci on brain MRI with learning disorders or severe motor incoordination in a group of 31 children. Duffner et al found no relation between hyperintense T2 foci on brain MRI and school problems or clinical findings in 47 children. ${ }^{5}$ Ferner et al studied 22 adults and 16 children and did not find an association between lower intelligence and the presence or the number of enhanced T2 weighted foci in the brain. ${ }^{4}$

Recently, however, two studies did show a negative association between enhanced $\mathrm{T} 2$ weighted foci in the brain of patients with neurofibromatosis type 1 and intelligence. The study by Hofman et $\mathrm{al}^{16}$ focused on 12 sibling pairs, in whom only one of the sibs had neurofibromatosis type 1 . They found a significant correlation between the lowering of IQ in the siblings with neurofibromatosis type 1 and the number of locations with T2 weighted hyperintensities in the brain. A remarkable finding was that 11 of 12 children

Table 2 Relation between full scale IQ (FSIQ) and T2 weighted enhanced foci

\begin{tabular}{|c|c|c|c|c|c|c|c|}
\hline \multirow{2}{*}{$\begin{array}{l}\text { Dependent } \\
\text { variable }\end{array}$} & \multirow{2}{*}{$\begin{array}{l}\text { Independent } \\
\text { variable }\end{array}$} & \multirow{2}{*}{$\begin{array}{l}\text { Patients with } \\
\text { foci in Brain (n) }\end{array}$} & \multirow{2}{*}{$\begin{array}{l}\text { Patients with } \\
\text { Foci in } R I(n)\end{array}$} & \multicolumn{2}{|c|}{ Mean FSIQ } & \multirow[b]{2}{*}{ F ratio } & \multirow[b]{2}{*}{$P$ value } \\
\hline & & & & Foci- & Foci + & & \\
\hline FSIQ & No of foci & 18 & - & - & - & 2.51 & 0.085 \\
\hline FSIQ & $\begin{array}{l}\text { Frontal lobe } \\
\text { Cerebellar hemisphere } \\
\text { Internal capsule } \\
\text { Thalamus } \\
\text { Basal ganglia } \\
\text { Medulla oblongata }\end{array}$ & & $\begin{array}{l}3 \\
4 \\
8 \\
3 \\
4 \\
4\end{array}$ & $\begin{array}{l}88 \cdot 2 \\
86 \cdot 2 \\
85 \cdot 7 \\
88 \cdot 6 \\
85 \cdot 9 \\
87 \cdot 9\end{array}$ & $\begin{array}{r}91 \cdot 3 \\
102 \cdot 6 \\
95 \cdot 6 \\
85 \cdot 8 \\
104 \cdot 5 \\
92 \cdot 4\end{array}$ & $\begin{array}{l}0.06 \\
3 \cdot 49 \\
1 \cdot 60 \\
0 \cdot 08 \\
4 \cdot 64 \\
0 \cdot 24\end{array}$ & $\begin{array}{l}0.814 \\
0.07 \\
0 \cdot 22 \\
0.78 \\
0.04^{\star} \\
0.63\end{array}$ \\
\hline
\end{tabular}

Covariance analysis with FSIQ as dependent variable and the presence of hyperintense foci in total and in each of the specific regions of interest $(\mathrm{RI})$ as independent variables. Age and the presence of neurological problems are used as covariants. The group with foci in the specific RI has a higher FSIQ than the rest, except for the thalamus region.

* Indicates that the difference in FSIQ is significant at the $5 \%$ level for the basal ganglia region. This marginal significance probably results from multiple testing and should not be considered as real. 
with neurofibromatosis type 1 showed T2 weighted hyperintensities, which is higher than in any other reported study. North et al ${ }^{15}$ studied 40 children without major neurological problems or frank mental retardation and found a bimodal distribution of FSIQ. Those with T2 weighted hyperintensities in the brain had a significantly lower total IQ than those without. In this study there was no correlation of FSIQ with the number or location of T2 weighted hyperintensities.

The previous studies all differed in design (age groups, socioeconomic classes, sibling comparison) and they comprised relatively few subjects. These may be explanations for the different conclusions. Another explanation for these contradicting results may be that two or more different kinds of enhanced T2 weighted foci exist, those representing some kind of brain abnormality, and those not representing brain alterations. The eight children with other neurological disease in this study all showed T2 weighted hyperintense foci, and these foci might be different from those in the group without other neurological disease. Moreover, it is known that some T2 weighted hyperintensities in the brains of patients with neurofibromatosis type 1 disappear with time and it is possible to find them only at a certain age. ${ }^{18}$ In the different studies the different relative proportion of these possibly different kinds of T2 weighted hyperintensities and the different ages when MRI was carried out might explain the opposite conclusions.

A larger set of patients with neurofibromatosis type 1 should be tested in a multicentre study to gain more insight into the possible association of cognitive problems in neurofibromatosis type 1 and T2 weighted enhanced foci in the brain. In this study investigators should use a standard protocol for patient selection, timing of MRI, and reporting of MRI abnormalities. In the mean time there is no good reason to suspect a mental problem when enhanced T2 weighted foci are found in the brain of a child with neurofibromatosis type 1 without other neurological disease.

We thank Dr Gene Fisch, Brooklyn, New York, for critically reading the manuscript and for helpful suggestions. Part of this work is published in the PhD thesis of EL.

1 Riccardi VM, Eichner JE. Neurofibromatosis: phenotype, natural history and pathogenesis. Baltimore: Johns Hopkins University Press, 1988.

2 Viskochil D, White R, Cawthon R. The neurofibromatosis type 1 gene. Annu Rev Neurosci 1993;16:183-205.

3 Dunn DW, Roos KL. Magnetic resonance imaging evaluation of learning difficulties and incoordination in neurofibromatosis. Neurofibromatosis 1989;2:1-5.

4 Ferner RE, Chaudhuri R, Bingham J, Cox T, Hughes RAC. MRI in neurofibromatosis 1 . The nature and evolution of increased intensity T2 weighted lesions and their relationship to intellectual impairment. $\mathcal{F}$ Neurol Neurosurg Psychiatry 1993;56:492-5.

5 Duffner PK, Cohen ME, Seidel FG, Shucard DW. The significance of MRI abnormalities in children with neurofibromatosis. Neurology 1989;39:373-8.

6 DiMario FJ Jr, Ramsby G, Greenstein R, Langshur S, Dunham $B$. Neurofibromatosis type 1: magnetic resonance imaging findings. $\mathcal{F}$ Child Neurol 1993;8:32-9.

7 Ferner RE. Intellect in neurofibromatosis type 1. In: Huson SM, et al, eds. The neurofibromatoses: a pathogenic and clinical overview. London: Chapman and Hall, 1994:233-52.

8 Eldridge R, Denckla MB, Bien E, et al. Neurofibromatosis type 1 (Recklinghausen's disease). Neurologic and cognitive assesment with sibling controls. $\mathrm{Am} \mathcal{F}$ Dis Child 1989;56:492-5.

9 Eliason MJ. Neurofibromatosis: implications for learning and behavior. $\mathcal{F}$ Dev Behav Pediatr 1986;7:175-9.

10 Varnhagen CK, Lewin S, Das JP, Bowen P, Ma K Klimek M. Neurofibromatosis and psychological processes. F Dev Behav Pediatr 1988;9:257-65.

11 Legius E, Descheemaeker MJ, Spaepen A, Casaer P, Fryns JP. Neurofibromatosis type 1 in childhood: a study of the neuropsychological profile in 45 children. Genet Couns 1994;5:51-60.

12 Eliason MJ. Neuropsychological patterns: neurofibromatosis compared to developmental learning disorders. Meurofibromatosis $1988 ; 1: 17-25$.

13 Wadsby $M$, Lindehammar $H$, Eeg-Olofsson O. Neurofibromatosis in childhood: neuropsychological aspects. Neurofibromatosis 1989;2:251-60.

14 Stine SB, Adams WV. Learning problems in neurofibromatosis patients. Clin Orthop 1989;245:43-8.

15 North K, Joy P, Yuille D, et al. Specific learning disability in children with neurofibromatosis type 1: significance of MRI abnormalities. Neurology 1994;44:878-83.

16 Hofman KJ, Harris EL, Bryan RN, Denckla MB. Neurofibromatosis type 1: the cognitive phenotype. $f$ Pediatr 1994;124:S1-8.

17 Stumpf DA, Alksne JF, Annegers JF, et al. Neurofibromatosis conference statement. Arch Neurol 1988;45: 575-8.

18 Itoh T, Magnaldi S, White RM, et al. Neurofibromatosis type 1: the evolution of deep gray and white matter MR abnormalities. AfNR Am $\mathcal{F}$ Neuroradiol 1994;15:1513-9. 